\title{
Efficacy of local dexmedetomidine add-on for spermatic cord block anesthesia in patients undergoing intrascrotal surgeries: randomized controlled multicenter clinical trial
}

This article was published in the following Dove Press journal: Journal of Pain Research

8 November 2017

Number of times this article has been viewed

\author{
Diab Fuad Hetta' \\ Emad E Kamal ${ }^{2}$ \\ Ali M Mahran² \\ Doaa G Ahmed' \\ Abdelraheem Elawamy ${ }^{3}$ \\ Abdelraouf MS Abdelraouf ${ }^{3}$ \\ 'Department of Anesthesiology \\ and Pain Management, South Egypt \\ Cancer Institute, ${ }^{2}$ Department \\ of Dermatology and Andrology, \\ ${ }^{3}$ Department of Anesthesiology and \\ Intensive Care, Faculty of Medicine, \\ Assiut University, Assiut, Egypt
}

Study objective: The objective of this study was to evaluate the effect of adding dexmedetomidine (DEX) to bupivacaine on the quality of spermatic cord block anesthesia and postoperative analgesia.

Design: This is a randomized, double-blind study.

Setting: This study was performed in an educational and research hospital.

Patients: One hundred twenty adult males were scheduled for intrascrotal surgeries.

Interventions: Patients were divided into two groups: group B received $10 \mathrm{~mL}$ of bupivacaine $0.25 \%$ for spermatic cord block and intravenous $50 \mu \mathrm{g}$ of DEX and group BD received $10 \mathrm{~mL}$ of bupivacaine $0.25 \%$ added to $50 \mu \mathrm{g}$ of DEX $(9.5 \mathrm{~mL}$ bupivacaine $0.25 \%+0.5 \mathrm{~mL}$ [50 $\mu \mathrm{g}$ ] DEX) for spermatic cord block, and for masking purposes, the patients received isotonic saline intravenously.

Measurements: Time to first analgesic request, analgesic consumption, and visual analog scale (VAS) pain score in the first 24 hours postoperatively were assessed.

Main results: Time to first rescue analgesic was significantly delayed in group $\mathrm{BD}$ in comparison with group B, median (interquartile) range, $7(6-12)$ hours versus $6(5-7)$ hours, $(p=0.000)$, the mean cumulative morphine consumption $(\mathrm{mg})$ in the first postoperative 24 hours was significantly lower in group BD compared with group B, $8.13 \pm 4.45$ versus $12.7 \pm 3.79$, with a mean difference $(95 \% \mathrm{CI})$ of $-4.57(-6.06$ to -3.07$)(p=0.000)$; also, there was a significant reduction of VAS pain score in group BD in comparison with group B at all measured time points, VAS 2 hours $(1.28 \pm 0.9$ vs $1.92 \pm 0.8)$, VAS 6 hours $(2.62 \pm 1.5$ vs $3.93 \pm 1.2)$, VAS 12 hours $(2.40 \pm 1.1$ vs $3.57 \pm 0.65)$, VAS 24 hours $(1.90 \pm 0.68$ vs $2.53 \pm 0.62)(p=0.000)$

Conclusion: The addition of $50 \mu \mathrm{g}$ of DEX to bupivacaine $0.25 \%$ in spermatic cord block for intrascrotal surgeries resulted in delay of first analgesic supplementation, reduction of postoperative analgesic consumption as well as improvement of the success rate of the block.

Keywords: dexmedetomidine, spermatic cord, intrascrotal surgery

\section{Introduction}

Spermatic cord block has been done safely for many intrascrotal surgeries including operations on the testis, epididymis, and spermatic cord. It involves blocking of the genital branch of the genitofemoral nerve and the ilioinguinal nerve after their emergence from the external ring of the inguinal canal as well as the sympathetic plexuses of nerves around the cord. ${ }^{1}$ Spermatic cord block anesthesia offers the advantages of avoiding the undesirable side effects of general and neuraxial anesthesia, along with increased dura-
Correspondence: Diab Fuad Hetta Department of Anesthesiology and Pain Management, South Egypt Cancer Institute, Assiut University, Assiut, Egypt Tel +20 109 1090009

Fax +20882348609

Email diabhetta25@gmail.com 
tion of postoperative pain relief, ${ }^{2,3}$ reduced hospital stay and decreased financial burden. ${ }^{4}$ The short duration of peripheral nerve blocks limits their role in the improvement of postoperative analgesia. Hence, several local anesthetic adjuvants have been used perineurally to improve the effect of local anesthetics such as opioids, ${ }^{5,6}$ clonidine, ${ }^{7}$ dexamethasone, ${ }^{8}$ magnesium, ${ }^{9}$ midazolam, and ketamine. ${ }^{10}$ Dexmedetomidine (DEX) is a potent and a highly selective $\alpha-2$ adrenoceptor agonist that owes sympatholytic, sedative, and analgesic properties. ${ }^{11,12}$ Animal studies have shown that DEX fastens the onset of sensory and motor blockade along with increased duration of analgesia. ${ }^{13,14}$ In human studies, the addition of DEX to local anesthetics has shown to improve the quality of some regional blocks and prolong the duration of postoperative analgesia. ${ }^{15-17}$

The aim of this study was to evaluate the effect of adding DEX to bupivacaine on the quality of spermatic cord block anesthesia and postoperative analgesia.

\section{Methods}

\section{Ethical approval and registration}

This study was approved by the ethical committee of the faculty of medicine and institutional review board of South Egypt Cancer Institute, Assiut University, and written informed consent was obtained from each patient. The study was performed at the Andrology Department, Assiut University Hospital and South Egypt Cancer Institute, Assiut University, Egypt. The trial was registered in www.pactr.org; the identification number for the registry is PACTR201506001158296.

\section{Inclusion and exclusion criteria}

One hundred and twenty adult males, scheduled for intrascrotal surgery were enrolled. Exclusion criteria included refusal of regional anesthesia, allergy to study drugs (bupivacaine, DEX, or morphine), bleeding disorders, infection in the inguinoscrotal region, history of drug or alcohol abuse, and patients suffering from chronic pain or treated with regular analgesics.

\section{Randomization and blindness}

Patients were randomly allocated using block randomization method to two groups, group $B(n=60)$ received spermatic cord block with bupivacaine only and group BD $(n=60)$ received spermatic cord block with a mixture of bupivacaine and DEX.

Coded study drug solutions were prepared by anesthesiologist assistant, and the solutions were handed over to the concerned anesthesiologist for administration. According to the randomization code for each patient, group $\mathrm{B}$ received $10 \mathrm{~mL}$ of bupivacaine $0.25 \%$ for spermatic cord block and intravenous $50 \mu \mathrm{g}$ of DEX (Precedex ${ }^{\circledR}$, Hospira, Lake Forest, IL, USA) (diluted in $50 \mathrm{~mL}$ isotonic saline and delivered by syringe pump, programmed to give $1 \mathrm{~mL}$ per minute or group $\mathrm{BD}$ received $10 \mathrm{~mL}$ of bupivacaine $0.25 \%$ added to $50 \mu \mathrm{g}$ of DEX $(9.5 \mathrm{~mL}$ bupivacaine $0.25 \%+0.5 \mathrm{~mL}$ [50 $\mu \mathrm{g}]$ DEX) for spermatic cord block, and for masking purposes, the patients received isotonic saline intravenously via $50 \mathrm{~mL}$ syringe pump, programmed to give $1 \mathrm{~mL}$ per minute.

The night before surgery, oral lorazepam $4 \mathrm{mg}$ was given. Upon arrival at the operating room, a peripheral venous line was inserted. Monitoring probes (electrocardiography, noninvasive blood pressure, pulse oximeter) were attached.

\section{Technique of the block}

After sterilization of inguino-scrotal region, the spermatic cord is palpated at the neck of scrotum and under ultrasound (US) guidance (M-Turbo; SonoSite Inc., Bothell, WA, USA) using a linear transducer $10 \mathrm{MHz}$. The spermatic cord was identified as a half-circle structure containing the testicular artery identified by Doppler US and the vas deferent as a round non-compressible structure with no Doppler flow through it. The overlying skin was infiltrated with $2 \mathrm{~mL}$ of $1 \%$ lidocaine, 22 gauge block needle attached to extension tube was inserted toward the vas deferent under out-of-plane real-time US guidance, and just before touching the vas, $10 \mathrm{~mL}$ of prepared solution was injected around it.

In cases of insufficient block, according to the degree of patient's discomfort, the patient received either additional local anesthetic (from the same prepared solution), additional analgesics (fentanyl boluses, $50 \mu \mathrm{g}$ fentanyl), or conversion to general anesthesia, which entailed induction with propofol $2-3 \mathrm{mg} / \mathrm{kg}$, maintenance with sevoflurane $2 \%-3 \%$ in $50 \%$ oxygen and air, and securing the airway with the insertion of suitable size laryngeal mask.

After the end of surgery, the patients were transferred to day care unit for 24 hours observation period. Our postoperative analgesic protocol was intravenous patient controlled analgesia (PCA) morphine, programed to deliver $2 \mathrm{mg}$ bolus with 5 minutes lock out interval and without background infusion.

\section{Study outcomes}

Our primary end point was the time to first analgesic demand and the secondary end points were 1) the success rate of the block (the block was considered unsuccessful if any additional intraoperative local anesthetic, analgesic, or sedative was used, and/or VAS score was $>3$ or conversion to general anesthesia), 2) 24 hours analgesic consumption, 3) the VAS score measured at $2,6,12$, and $24 \mathrm{~h}$ postoperatively, and 
4) the level of sedation assessed using Observer's Assessment of Alertness/Sedation Scale (OAA/S). Scores $\leq 3$ were considered excessive sedation.

\section{Statistical analysis}

Based on a previous study, ${ }^{18}$ which reported a mean difference of 1.95 hours of postoperative analgesic duration and a standard deviation (SD) of 4.43 for the bupivacaine only group and 2.73 for the bupivacaine + DEX group, it was estimated that a minimum sample size of 57 patients in each study group would achieve a power of $80 \%$, assuming a type 1 error of 0.05 . We enrolled 120 patients to allow for dropouts. Statistical analysis was carried out on a personal computer using SPSS version 20 software. Normality of continuous data distribution was tested with the AndersonDarling test prior to further statistical analysis. Categorical data were described as number and percent, where continuous data were described as mean \pm SD or $95 \%$ confidence interval (CI) where appropriate. Chi-square test was used for comparison between categorical variables, where continuous variables were compared using unpaired Student's $t$-test. Time to first analgesic request was not normally distributed, and data were described as median (interquartile range). General linear model was used for the analysis of repeated measures of VAS pain score over time to detect the overall effect of group, time, and group-by-time interaction, and subsequent multiple comparisons were achieved by post hoc tests and type 1 error was controlled with Bonferroni correction. Statistical significance was set at $p<0.05$.

\section{Results}

There was no statistically significant difference between the two groups with respect to demographic data, type, and duration of surgery (Table 1).
The time to first rescue analgesic was significantly delayed in group $\mathrm{BD}$ in comparison with group $\mathrm{B}$, median (interquartile) range, 7 (6-12) hours versus $6(5-7)$ hours, respectively, $p=0.000$ (Figure 1 ).

The mean cumulative morphine consumption $(\mathrm{mg})$ in the first postoperative 8 hours was significantly lower in group BD compared with group B, 2.23 2 2.21 versus 3.97 \pm 2.28 , with an estimated mean difference $(95 \% \mathrm{CI})$ of $-1.73(-2.55$ to -0.92 ), also the mean cumulative morphine consumption (mg) in the first postoperative 16 hours was significantly lower in group BD compared with group B, 5.33 \pm 3.41 versus $9.1 \pm 3.05$, with an estimated mean difference $(95 \% \mathrm{CI})$ of $-3.77(-4.93$ to -2.6$)$; moreover, the mean cumulative morphine consumption (mg) in the first postoperative 24 hours was significantly lower in group BD compared with group B, $8.13 \pm 4.45$ versus $12.7 \pm 3.79$, with an estimated mean difference $(95 \% \mathrm{CI})$ of -4.57 ( -6.06 to -3.07$)$ (Table 2$)$.

The general linear model for repeated measures of VAS pain score over time revealed significant reduction of overall VAS pain score in group BD in comparison with group B, 2.05 versus 2.99 with an estimated mean difference $(95 \%$ CI) of $-0.94(-1.18$ to -0.69$)(p=0.000)$. Moreover, there was a significant reduction of VAS pain score in group BD in comparison with group B at all measured time points, VAS 2 hours $(1.28 \pm 0.9$ vs $1.92 \pm 0.8)$, VAS 6 hours $(2.62 \pm 1.5$ vs $3.93 \pm 1.2)$, VAS 12 hours $(2.40 \pm 1.1$ vs $3.57 \pm 0.65)$, VAS 24 hours $(1.90 \pm 0.68$ vs $2.53 \pm 0.62)(p=0.000)$ (Figure 2$)$.

The failure rate of the block was significantly higher in group $\mathrm{B}$ in comparison with group $\mathrm{BD}(11.67 \%$ vs $3.3 \%)(p=0.005)$. The failure dynamics of the block were shown in (Table 3 ).

Regarding the perioperative hemodynamics, there were statistically significant reductions in the intraoperative mean heart rate and mean arterial blood pressure in the BD group at the following time points $(15,20,25$, and 30 minutes) (Figure 3 ).

Table I Demographic data

\begin{tabular}{|c|c|c|c|}
\hline Variables & $\begin{array}{l}\text { Group B } \\
(n=60)\end{array}$ & $\begin{array}{l}\text { Group BD } \\
(n=60)\end{array}$ & p-value \\
\hline Age (years) & $36.9(34.9-39.3)$ & $37.8(42.8-40.2)$ & 0.936 \\
\hline BMI $\left(\mathrm{kg} / \mathrm{m}^{2}\right)$ & $28(26.2-28.9)$ & $27.7(26.8-29.3)$ & 0.532 \\
\hline ASA grade $I / I I / I I I$ & $47 / 10 / 3$ & $50 / 7 / 3$ & 0.594 \\
\hline \multicolumn{4}{|l|}{ Type of operations } \\
\hline Testicular biopsy & 34 & 36 & 0.921 \\
\hline Orchidectomy & II & 12 & 0.975 \\
\hline Epidydimal cystectomy & 8 & 5 & 0.521 \\
\hline Spermatocoelectomy & 3 & 4 & 0.876 \\
\hline Epidydmovasostomy & 4 & 3 & 0.876 \\
\hline Duration of surgery (minutes) & $37.1(30.4-41.6)$ & $36.7(30.5-4 I)$ & 0.832 \\
\hline
\end{tabular}

Notes: Values are expressed as the mean $(95 \% \mathrm{Cl})$ or absolute numbers. B refers to bupivacaine group and BD to bupivacaine $+\mathrm{DEX}$ group. Abbreviations: BMI, body mass index; ASA, American Society of Anesthesiologists; DEX, dexmedetomidine. 


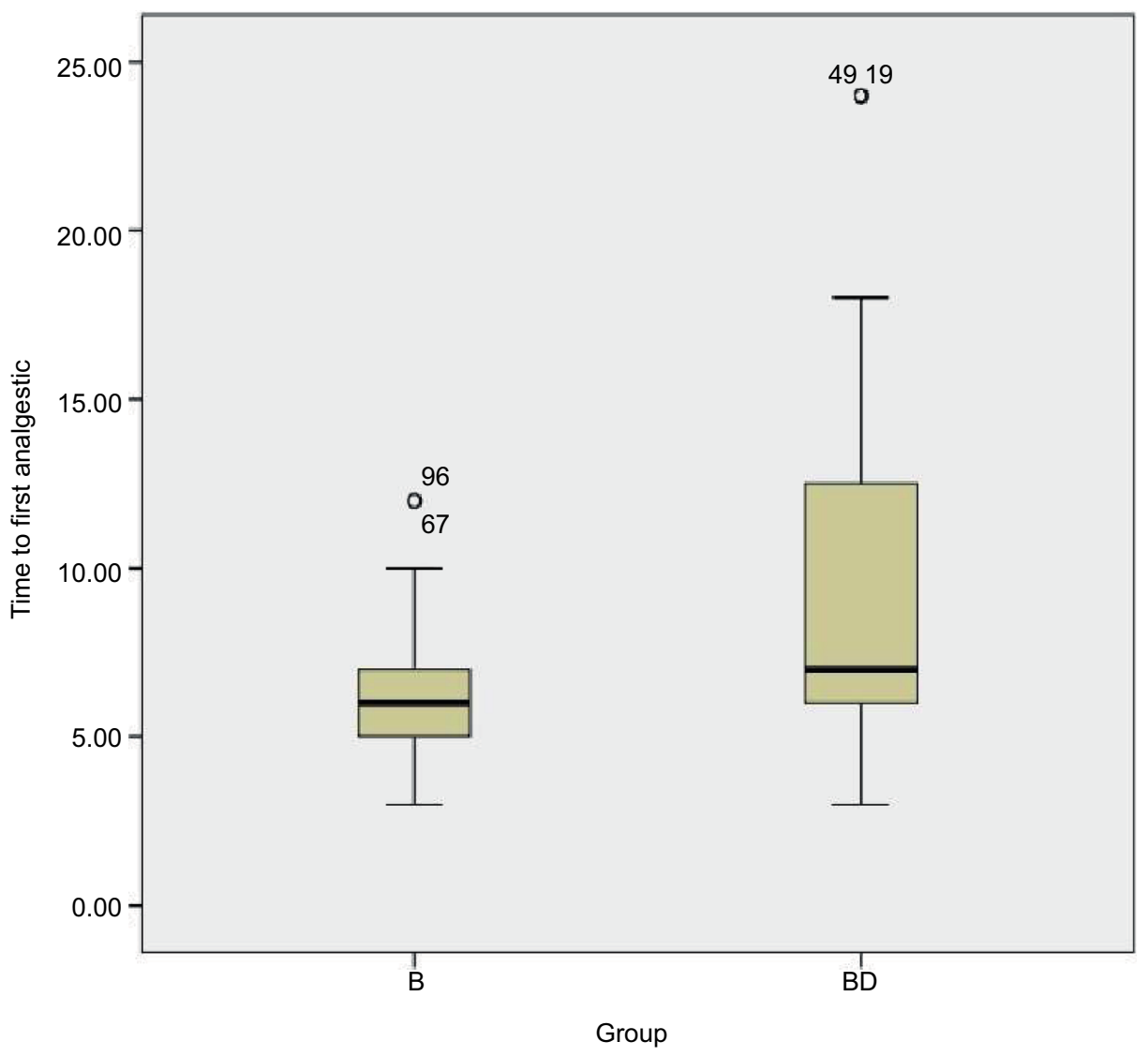

Figure I A box plot of postoperative time (hours) to rescue analgesic in each group. The middle line in each box represents the median value, the outer margins of the box represent the interquartile range, and the whiskers represent the 10th and 90th percentile. Circles represent the outliers. B refers to bupivacaine group and BD to bupivacaine + DEX group.

Abbreviation: DEX, dexmedetomidine.

Table 2 Cumulative postoperative 24 hours PCA morphine consumption and overall 24 hours VAS pain score

\begin{tabular}{lllll}
\hline $\begin{array}{l}\text { Morphine } \\
\text { consumption (mg) }\end{array}$ & $\begin{array}{l}\text { Group BD } \\
\mathbf{( N = 6 0 )}\end{array}$ & $\begin{array}{l}\text { Group B } \\
\mathbf{( N = 6 0 )}\end{array}$ & $\begin{array}{l}\text { Mean } \\
\text { difference }\end{array}$ & $\begin{array}{l}\mathbf{9 5 \%} \mathbf{C l} \\
\text { (mean difference) }\end{array}$ \\
\hline Cumulative 8 hours & $2.23 \pm 2.21$ & $3.97 \pm 2.28$ & $-1.73^{\mathrm{a}}$ & -2.55 to -0.92 \\
Cumulative 16 hours & $5.33 \pm 3.41$ & $9.1 \pm 3.05$ & $-3.77^{\mathrm{a}}$ & -4.93 to -2.6 \\
Cumulative 24 hours & $8.13 \pm 4.45$ & $12.7 \pm 3.79$ & $-4.57^{\mathrm{a}}$ & -6.06 to -3.07 \\
Overall 24 hours VAS & 2.05 & 2.99 & $0.94^{\mathrm{a}}$ & -1.18 to $-0.69^{\mathrm{b}}$ \\
\hline
\end{tabular}

Notes: ${ }^{\mathrm{T} T h e}$ mean difference is significant at the 0.05 level. ${ }^{\mathrm{b}}$ Adjustment for multiple comparisons: Bonferroni. B refers to bupivacaine group and $\mathrm{BD}$ to bupivacaine $+\mathrm{DEX}$ group.

Abbreviations: PCA, patient controlled analgesia; VAS, visual analog scale; DEX, dexmedetomidine.

Regarding DEX-related sedation, we did not report significant statistical differences between the two groups (Figure 4).

\section{Discussion}

In the present study, the addition of $50 \mu \mathrm{g}$ of DEX to bupivacaine $0.25 \%$ for spermatic cord block for patients undergoing intrascrotal surgery resulted in significant delay of first analgesic demand, improved the success rate of the block, reduced postoperative analgesic consumption, and decreased pain intensity in the first postoperative 24 hours.
Kaye et al described the blind technique of the spermatic cord block, where they fixed the spermatic cord against the pubic tubercle and pierced it with a needle, inserted vertically to the pubic bone, ${ }^{19} 1 \mathrm{~cm}$ below and medial to the pubic tubercle, in addition to scrotal skin infiltration with local anesthetics. In the current study, we performed the spermatic cord block with the help of US guidance to avoid injury to testicular artery and vas deferent. ${ }^{1}$

DEX is a selective $\alpha_{-2}$ adrenoceptor agonist with an eightfold affinity compared to the $\alpha-{ }_{2}$ adrenoceptor, clonidine. ${ }^{20}$ 


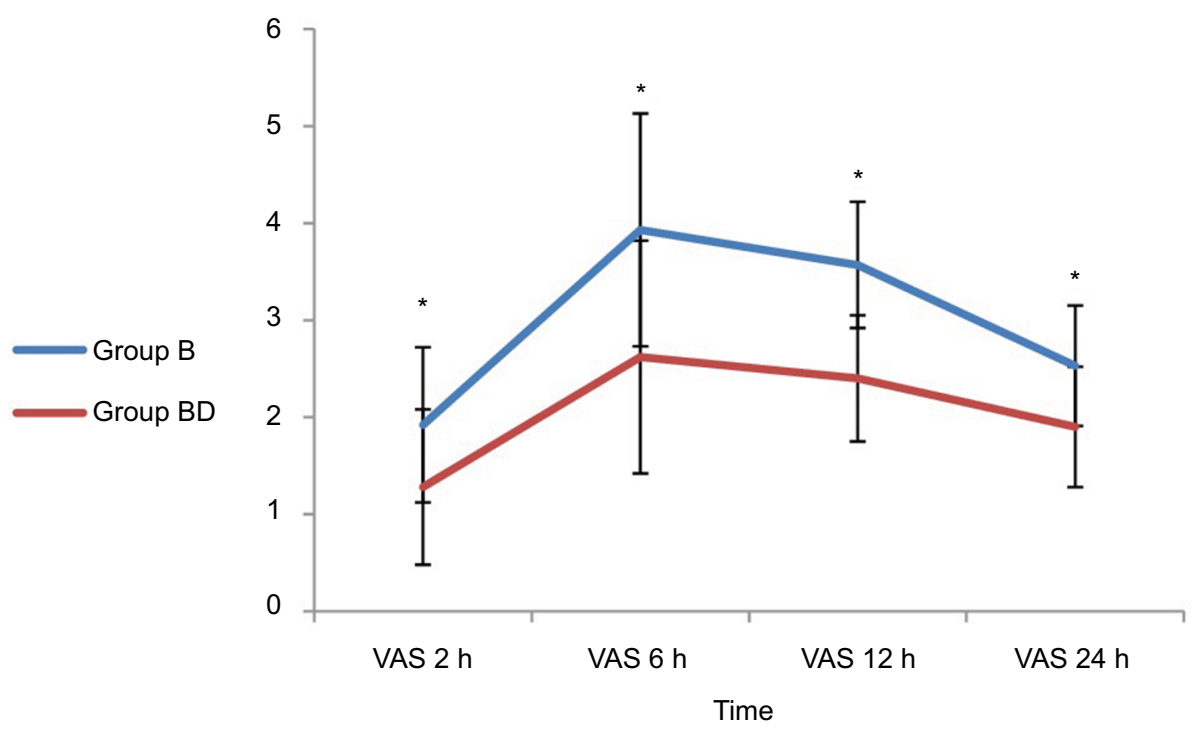

Figure $2 \mathrm{~A}$ line graph representing the postoperative VAS pain score in the two study groups. $* p<0.05$ between the groups. B refers to bupivacaine group and BD to bupivacaine + DEX group.

Abbreviation: VAS, visual analog scale; DEX, dexmedetomidine.

Table 3 Failure dynamics of spermatic cord block anesthesia

\begin{tabular}{llll}
\hline Variables & $\begin{array}{l}\text { Group B } \\
(\mathbf{n = 6 0 )}\end{array}$ & $\begin{array}{l}\text { Group BD } \\
(\mathbf{n = 6 0 )}\end{array}$ & p-value \\
\hline Failed block & $7(11.67 \%)$ & $2(3.3 \%)^{\mathrm{a}}$ & 0.005 \\
Additional analgesic (fentanyl) & $3(5 \%)$ & $1(1.67 \%)^{\mathrm{a}}$ & 0.032 \\
Additional local anesthetic & $4(6.6 \%)$ & $\mathrm{I}(1.67 \%)^{\mathrm{a}}$ & 0.021 \\
\hline
\end{tabular}

Notes: Values are expressed as absolute numbers (\%). ${ }^{a} p$-value $<0.05$. B refers to bupivacaine group and BD to bupivacaine + DEX group.

Abbreviation: DEX, dexmedetomidine.

It possesses a unique sedative, anxiolytic, and analgesic criteria. $^{21,22}$

The usage of DEX as a local anesthetic adjuvant is inspired from its prototype clonidine, which enhanced the activity-dependent hyperpolarization generated by the sodium-potassium pump and consequently blocked the conduction of pain impulses. ${ }^{23}$

There is a great variability of DEX doses when it is used as a local anesthetic adjuvant, ${ }^{24-28}$ because the clinical studies are different in between in defining bradycardia and hypotension, ${ }^{28-30}$ which are the main drawbacks of DEX usage. As there were no previous reference dosage guidelines of DEX for spermatic cord block, the selection of the DEX dose (50 $\mu \mathrm{g})$ was based on our own anecdotal experience.

Our study showed that the success rate of the block was significantly improved in group BD (96.7\%) compared with group B (88.4\%), while it was $90 \%-95 \%$ for blindly injected spermatic cord blocks in previous studies. ${ }^{4,93}$ It deserves mentioning that these studies administered additional local anesthetics and systemic analgesics during surgery that was considered failed blocks by our own study criteria for unsuccessful blocks. Moreover, we attempted diluted bupivacaine $(0.25 \%)$ for surgical block to declare any beneficial effects of DEX adjuvant, specifically bupivacaine sparing effect, while these studies administered local anesthetics with higher concentration (bupivacaine $0.5 \%$ and lidocaine $2 \%$ ).

Animal studies have declared that perineural DEX added to bupivacaine or ropivacaine prolongs the duration of sensory and motor block. ${ }^{13,14,32,33}$ Furthermore, human studies used DEX as local anesthetic adjuvants have been yielding prolonged block duration and decreased postoperative analgesic demand, but they are different in between regarding block characteristics. ${ }^{16,18,23,34,35}$ In this context, Fritsch et al reported that DEX added to ropivacaine extends the duration of interscalene brachial plexus blocks for elective shoulder surgery and minimized postoperative opioid supplementation. ${ }^{34}$ Esmaoglu et al found that DEX enhanced the onset of brachial plexus block, ${ }^{18}$ whereas Gandhi et al showed a delay in sensory and motor block onset time..$^{24}$ In our study, we could not assess the block onset as the nerves anesthetized in spermatic cord block the supply of intrascrotal contents and the scrotal skin is supplied by sensory branches from pudendal nerve that is anesthetized by local infiltration. However, we detected a significant prolongation of postoperative analgesic duration in DEX group along with significant reduction in postoperative analgesic consumption.

The main limitations of DEX are dose-dependent bradycardia and hypotension. ${ }^{36}$ In the present study, we observed a significant reduction in heart rate and mean blood pressure 


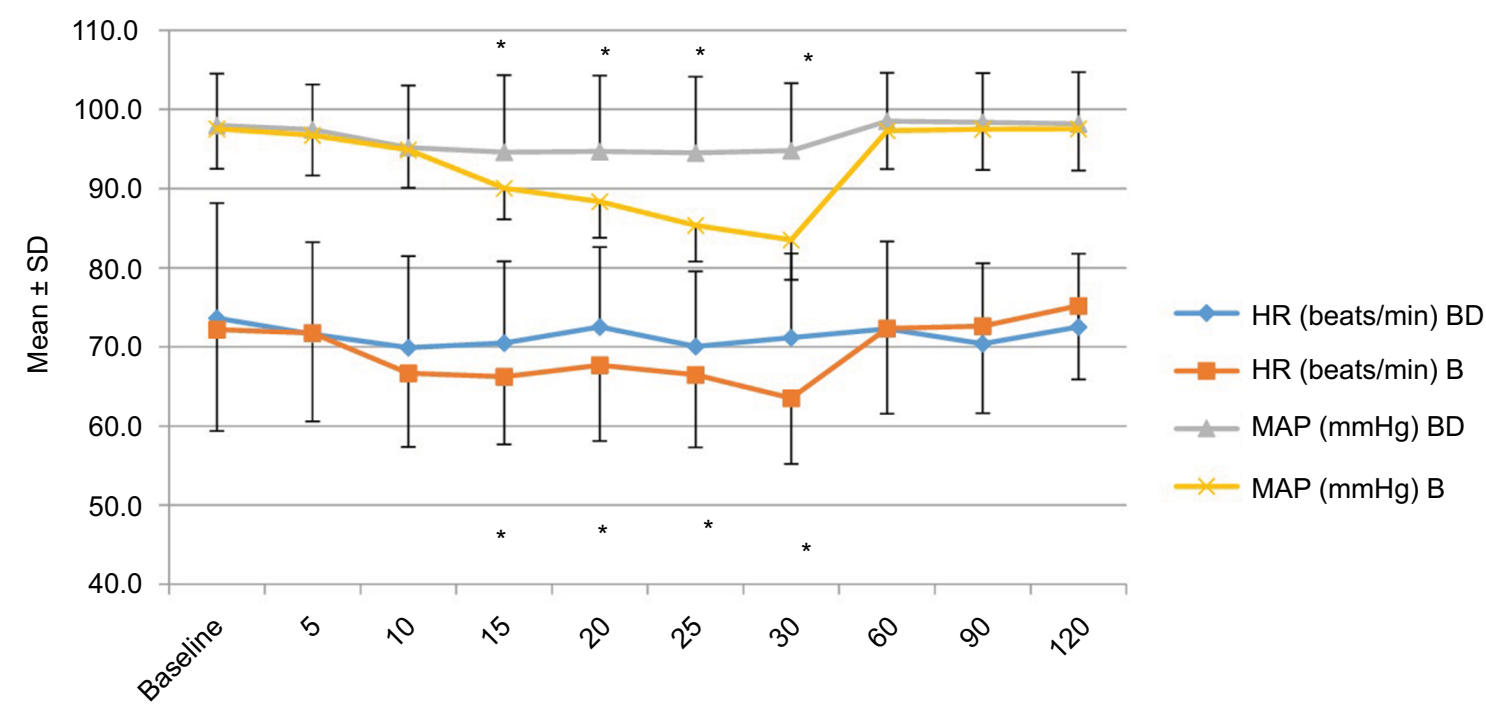

Time (min)

Figure $3 \mathrm{~A}$ line graph representing the perioperative HR and MAP in the two study groups. ${ }^{*} p<0.05$ between the groups. B refers to bupivacaine group and BD bupivacaine + DEX group.

Abbreviations: HR, heart rate; MAP, mean arterial blood pressure; DEX, dexmedetomidine.

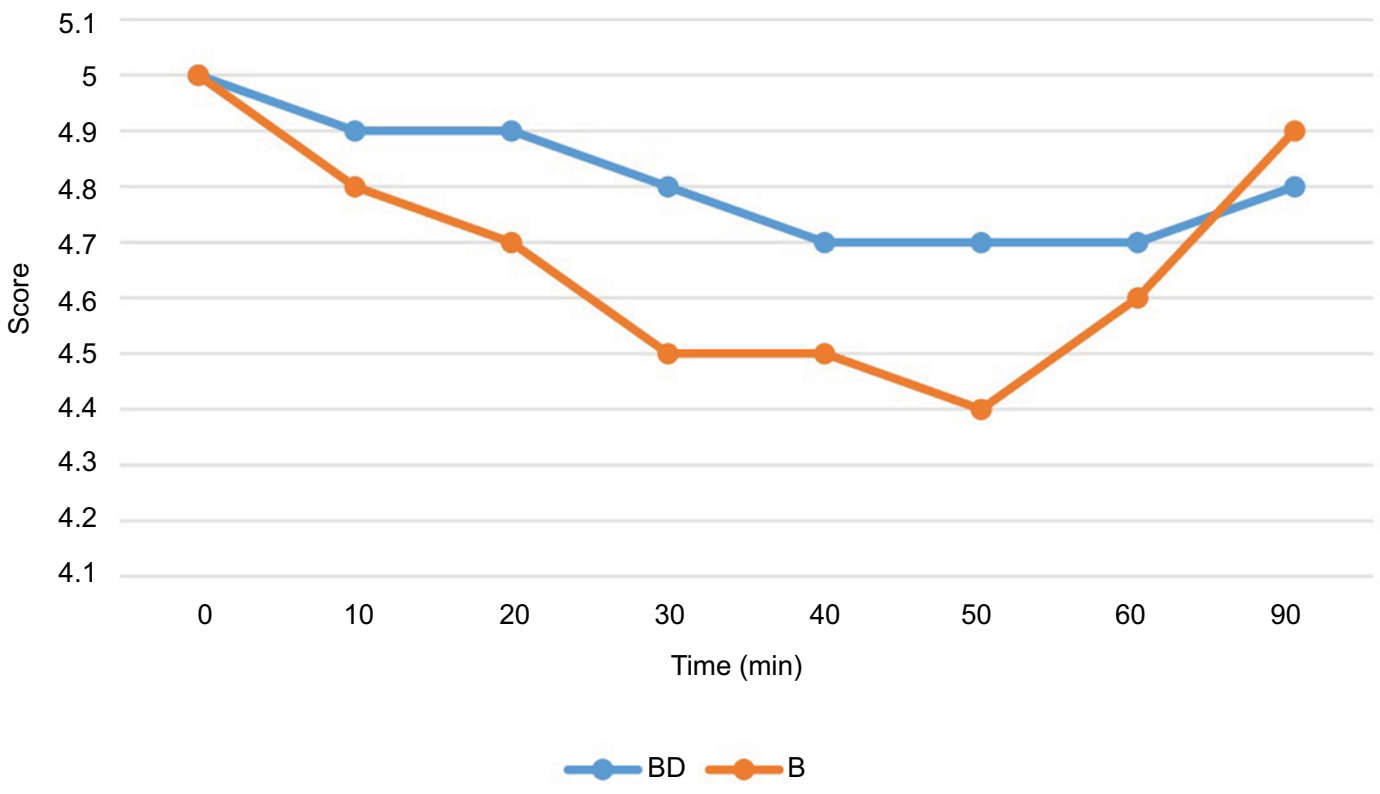

Figure $4 \mathrm{~A}$ line graph representing the OAA/S in the two study groups. B refers to bupivacaine group and BD to bupivacaine + DEX group.

Abbreviations: OAA/S, observer assessment of alertness and sedation score; DEX, dexmedetomidine.

intraoperatively, but they were in a safe limit and we did not report any cases of severe bradycardia or hypotension.

It is likely that the mechanisms by which DEX improved spermatic cord block are similar to the hypotheses suggested for perineural use of clonidine. ${ }^{37-41}$ Brummett et $\mathrm{al}^{33}$ suggested that the mechanism of perineural administration of DEX is by blocking the hyperpolarization-activated cation current, preventing the nerve from reaching the resting potential and capability of generation of subsequent action potential, thus
DEX decreases firing of pain impulse specifically from unmyelinated C-fibers. This is the most well-defined mechanism of perineural DEX. ${ }^{33}$

There are a rising conflicts among researchers whether DEX as a local anesthetic adjuvant acts through a peripheral or central mechanism. To eliminate the concerns about a possible systemic analgesic mechanism of DEX due to systemic absorption of DEX from the pampiniform plexuses of veins around spermatic cord, we administered group B the same 
dose of DEX ( $50 \mu \mathrm{g})$ used for group BD, but through intravenous routes. Abdallah et al reported a similar prolongation of an interscalene block whether DEX was administered perineurally or systemically in patients undergoing arthroscopic shoulder surgery, ${ }^{42}$ while Andersen et al concluded that DEX prolongs the duration of the saphenous nerve block by a peripheral mechanism when controlling for systemic effects, but not necessarily to a clinically relevant extent. ${ }^{43}$

In conclusion, the addition of $50 \mu \mathrm{g}$ of DEX to bupivacaine $0.25 \%$ in spermatic cord block for intrascrotal surgery resulted in significant improvement of the success rate of the block, delayed first demand for analgesic supplementation, and reduced postoperative analgesic consumption.

\section{Disclosure}

The authors report no conflicts of interest in this work.

\section{References}

1. Wipfli M, Birkhäuser F, Luyet C, Greif R, Thalmann G, Eichenberger U.Ultrasound-guided spermatic cord block for scrotal surgery. $\mathrm{Br} \mathrm{J}$ Anaesth. 2011;106(2):255-259.

2. Ezeh UI, Shepherd S, Moore HD, Cooke ID. Morbidity and costeffectiveness analysis of outpatient analgesia versus general anaesthesia for testicular sperm extraction in men with azoospermia due to defects in spermatogenesis. Hum Reprod. 1999;14:321-328.

3. Burden RJ, O'Kelly SW, Sutton D, Cumming J. Spermatic cord block improves analgesia improves analgesia for day case testicular surgery. Br J Urol. 1997;80(3):472-475.

4. Issa MM, Hsiao K, BasselYS, Bouet R, Young MR, Petros JA. Spermatic cord anesthesia block for scrotal procedures in outpatient clinic setting. J Urol. 2004;172:2358-2361.

5. Axelsson K, Gupta A. Local anaesthetic adjuvants: neuraxial versus peripheral nerve block. Curr Opin Anaesthesiol. 2009;22:649-654.

6. Popping DM, Elia N, Marret E, Wenk M, Tramer MR. Opioids added to local anaesthetics for single-shot intrathecal anaesthesia in patients undergoing minor surgery: a meta-analysis of randomized trials. Pain. 2012;153:784-793.

7. McCartney CJ, Duggan E, Apatu E. Should we add clonidine to local anesthetic for peripheral nerve blockade? A qualitative systematic review of the literature. Reg Anesth Pain Med. 2007;32:330-338.

8. Parrington S, O'Donnell D, Chan VW, et al. Dexamethasone added to mepivacaine prolongs the duration of analgesia after supraclavicular brachial plexus blockade. Reg Anesth Pain Med. 2010;35:422-426.

9. Buvanendran A, McCarthy RJ, Kroin JS, Leong W, Perry P, Tuman $\mathrm{KJ}$. Intrathecal magnesium prolongs fentanyl analgesia: a prospective, randomized, controlled trial. Anesth Analg. 2002;95:661-666.

10. Murali Krishna T, Panda NB, Batra YK, Rajeev S. Combination of low doses of intrathecal ketamine and midazolam with bupivacaine improves postoperative analgesia in orthopaedic surgery. Eur J Anaesthesiol. 2008;25:299-306.

11. Carollo DS, Nossaman BD, Ramadhyani U. DEX: a review of clinical applications. Curr Opin Anaesthesiol. 2008;21:457-461.

12. Venn RM, Bradshaw CJ, Spencer R, et al. Preliminary UK experience of DEX, a novel agent for postoperative sedation in the intensive care unit. Anaesthesia. 1999;54:1136-1142.

13. Brummett CM, Norat MA, Palmisano JM, Lydic R. Perineural administration of DEX in combination with bupivacaine enhances sensory and motor blockade in sciatic nerve block without inducing neurotoxicity in rat. Anesthesiology. 2008;109:502-511.
14. Brummett CM, Padda AK, Amodeo FS, Welch KB, Lydic R._Perineural DEX added to ropivacaine causes a dose-dependent increase in the duration of thermal antinociception in sciatic nerve block in rat. Anesthesiology. 2009;111:1111-1119.

15. Zhang Y, Wang CS, Shi JH, et al. Perineural administration of DEX in combination with ropivacaine prolongs axillary brachial plexus block. Int J Clin Exp Med. 2014;7:680-685.

16. Marhofer D, Kettner SC, Marhofer P, Pils S, Weber M, Zeitlinger M. DEX as an adjuvant to ropivacaine prolongs peripheral nerve block: a volunteer study. Br J Anaesth. 2013;110:438-442.

17. Kanazi GE, Aouad MT, Jabbour-Khoury SI, et al. Effect of low-dose DEX or clonidine on the characteristics of bupivacaine spinal block. Acta Anaesthesiol Scand. 2006;50:222-227.

18. Esmaoglu A, Yegenoglu F, Akin A, Turk CY_DEX added to levobupivacaine prolongs axillary brachial plexus block. Anesth Analg. 2010;111:1548-1551.

19. Kaye KW, Lange PH, Fraley EE. Spermatic cord block in urologic surgery. J Urol. 1982;128:720-722.

20. Kamibayashi T, Maze M. Clinical uses of $\alpha-2$ adrenergic agonists. Anesthesiology. 2000;93:1345-1349.

21. Ebert TJ, Hall JE, Barney JA, Uhrich TD, Colinco MD. The effects of increasing plasma concentrations of dexmedetomidine in humans. Anesthesiology. 2000;93:382-394.

22. Talke P, Richardson CA, Scheinin M, Fisher DM. Postoperative pharmacokinetics and sympatholytic effects of dexmedetomidine. Anesth Analg. 1997;85:1136-1142.

23. Dalle C, Schneider M, Clergue F, et al. Inhibition of the $\mathrm{I}(\mathrm{h})$ current in isolated peripheral nerve: a novel mode of peripheral antinociception? Muscle Nerve. 2001;24:254-261.

24. Gandhi R, Shah A, Patel I. Use of DEX along with bupivacaine for brachial plexus block. National J Med Res. 2012;2:67-69.

25. Kathuria S, Gupta S, Dhawan I. DEX as an adjuvant to ropivacaine in supraclavicular brachial plexus block. Saudi JAnaesth. 2015;9(2):148-154.

26. Ammar AS, Mahmoud KM. Ultrasound-guided single injection infraclavicular brachial plexus block using bupivacaine alone or combined with DEX for pain control in upper limb surgery: a prospective randomized controlled trial. Saudi J Anaesth. 2012;6:109-114.

27. Swami SS, Keniya VM, Ladi SD, Rao R. Comparison of DEX and clonidine ( $\alpha-2$ agonist drugs) as an adjuvant to local anesthesia in supraclavicular brachial plexus block: a randomised double-blind prospective study. Indian J Anaesth. 2012;56:243-249.

28. Kaygusuz K. Effects of adding DEX to levobupivacaine in axillary brachial plexus block. Curr Ther Res Clin Exp. 2012;73:103-111.

29. Al-Mustafa MM, Abu-Halaweh SA, Aloweidi AS, et al. Effect of DEX added to spinal bupivacaine for urological procedures. Saudi Med J. 2009;30:365-370.

30. Abdallah FW, Brull R. Facilitatory effects of perineural DEX on neuraxial and peripheral nerve block: a systematic review and meta-analysis. Br J Anaesth. 2013;110(6):915-925.

31. Wakefield SE, Elewa AA. Spermatic cord block: a safe technique for intrascrotal surgery. Ann R Coll Surg Engl. 1994;76:401-402.

32. Brummett CM, Amodeo FS, Janda AM, Padda AK, Lydic R. Perineural dexmedetomidine provides an increased duration of analgesia to a thermal stimulus when compared with a systemic control in a rat sciatic nerve block. Reg Anesth Pain Med. 2010;35:427-431.

33. Brummett CM, Hong EK, Janda AM, et al. Perineural dexmedetomidine added to ropivacaine for sciatic nerve block in rats prolongs the duration of analgesia by blocking the hyperpolarization-activated cation current. Anesthesiology. 2011;115:836-843.

34. Fritsch G, Danninger T, Allerberger K, et al. Dexmedetomidine added to ropivacaine extends the duration of interscalene brachial plexus blocks for elective shoulder surgery when compared with ropivacaine alone: a single-center, prospective, triple-blind, randomized controlled trial. Reg Anesth Pain Med. 2014;39(1):37-47.

35. Esmaoglu A, Mizrak A, Akin A, Turk Y, Boyaci A. Addition of dexmedetomidine to lidocaine for intravenous regional anaesthesia. Eur $J$ Anaesthesiol. 2005;22:447-451. 
36. Bhana N, Goa KL, McClellan KJ. Dexmedetomidine. Drugs. 2000; 59:263-268.

37. Eisenach JC, De Kock M, Klimscha W. alpha-2Adrenergic agonists for regional anesthesia. Anesthesiology. 1996;85:655-674.

38. Gaumann DM, Brunet PC, Jirounek P. Clonidine enhances the effects of lidocaine on C-fiber action potential. Anesth Analg. 1992;74:719-725.

39. Duka I, Gavras I, Johns C, Handy DE, Gavras H. Role of the postsynaptic alpha-2 adrenergic receptor subtypes in catecholamine-induced vasoconstriction. Gen Pharmacol. 2000;34(2):101-106.

40. Snapir A, Koskenvuo J, Toikka J, et al. Effects of common polymorphisms in the alpha1-A, alpha2-B, beta-1 and beta-2adrenoreceptors on haemodynamic responses to adrenaline. Clin Sci. 2003;104(5):509-520.
41. Chotani MA, Mitra S, Su BY, et al. Regulation of alpha-(2) adrenoceptors in human vascular smooth muscle cells. Am J Physiol Heart Circ Physiol. 2004;286(1):H59-H67.

42. Abdallah FW, Dwyer T, Chan VW, et al. IV and perineural dexmedetomidine similarly prolong the duration of analgesia after interscalene brachial plexus block: a randomized, three-arm, triple-masked, placebocontrolled trial. Anesthesiology. 2016;124:683-695.

43. Andersen JH, Grevstad U, Siegel H, Dahl JB, Mathiesen O, Jæger P. Does dexmedetomidine have a perineural mechanism of action when used as an adjuvant to ropivacaine? A paired, blinded, randomized trial in healthy volunteers. Anesthesiology. 2017;126:66-73.

\section{Publish your work in this journal}

The Journal of Pain Research is an international, peer reviewed, open access, online journal that welcomes laboratory and clinical findings in the fields of pain research and the prevention and management of pain. Original research, reviews, symposium reports, hypothesis formation and commentaries are all considered for publication.

\section{Dovepress}

The manuscript management system is completely online and includes a very quick and fair peer-review system, which is all easy to use. Visit http://www.dovepress.com/testimonials.php to read real quotes from published authors. 